\title{
Prevalence, types and risk factors of congenital anomalies (A hospital Based study
}

\section{Amira M. Shalaby}

\begin{abstract}
Congenital anomalies (CA) are common causes of infant's and childhood deaths and disability.

Objectives: The aim of the study is to determine the prevalence, describe the types and risk factors of congenital anomalies among newborns admitted to Neonatal Intensive Care Unit (NICU) of a Children's Hospital.
\end{abstract}

Study design: It is a prospective observational study(analytic cross sectional study) was performed and screening of the newborn admitted at NICU of a Children's Hospital during the period of 6 months from 1 to $12-2017$ to the end of 5-2018. The sample was 346 newborns, 173 cases and 173 controls. We collected data using a record checklist and an interviewing questionnaire.

Results: There were a significant difference between cases and control concerning gestational age $(\mathrm{P}=0.001)$, single or multiple babies $(\mathrm{P}=0.002)$, residence $(\mathrm{P}=0.001)$, consanguineous marriage $(\mathrm{P}=0.01)$ and family history of unfavorable outcome $(\mathrm{P}=0.001)$. We also found that the most common type of congenital anomalies was gastrointestinal anomalies 63 cases (36.4\%) with trachea esophageal fistula 17 cases (27\%) being the most common GIT anomalies. Conclusion: The prevalence of congenital anomalies was $22.97 \%$. The most common anomalies were gastrointestinal anomalies (GIT), musculoskeletal anomalies, multiple anomalies and circulatory system anomalies. The risk factors were consanguineous marriage, positive family history, urban areas, full-term and singleton pregnancies.

Keywords:

Congenital anomalies (CA); Risk factors; Prevalence; Types

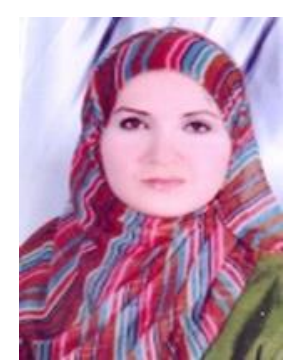

\section{Biography:}

Fatin Hasani was studied in School of Nursing and Midwifery, RCSI, Royal College of Surgeons in Ireland, Dublin

\section{Biography:}

Lecturer of Pediatrics, NICU Assiut University Children Hospital Faculty of Medicine, Assiut University, Assiut, Egypt

\section{Speaker Publications:}

1. "Altered Regulatory B Cell Subsets in Children with Type 1 Diabetes Mellitus”; Journal of Immunology Research: 2020 (1-8).

30th Neonatology and Primary Care Congress; Amsterdam, Netherlands; October 28 -29, 2020
Abstract Citation:
Amira M. Shalaby, Prevalence, types and risk factors of congenital anomalies (A hospital based study), Euro Neonatology 2020, 30th Neonatology and Primary Care Congress; Amsterdam, Netherlands; October 28 -29, 2020. (https://neonatalresearch.conferenceseries.com/abstract/2020/ prevalence-types-and-risk-factors-of-congenital-anomalies-a- hospital-based-study). 